Maria Concepcion F. Vitamog, MD

Samantha S. Castañeda, MD

Department of Otorhinolaryngology

Head and Neck Surgery

Jose R. Reyes Memorial Medical Center

Correspondence: Dr. Maria Concepcion F. Vitamog Department of Otorhinolaryngology - Head and Neck Surgery Jose R. Reyes Memorial Medical Center

San Lazaro Compound, Rizal Avenue

Sta. Cruz, Manila 1003

Philippines

Phone: (632) 743 6921; (632) 7119491 local 320

Email:entjrrmmc@yahoo.com

The authors declared that this represents original material that is not being considered for publication or has not been published or accepted for publication elsewhere, in full or in part, in print or in electronic media; that the manuscript has been read and approved by all the authors, that the requirements for authorship have been met by each author, and that each author believes that the manuscript represents honest work.

Disclosures: The authors signed disclosures that there are no financial or other (including personal) relationships, intellectual passion, political or religious beliefs, and institutional affiliations that might lead to a conflict of interest.

Presented at the Philippine Society of Otolaryngology Head and Neck Surgery Descriptive Research Contest (3rd Place). October 6, 2016. Natrapharm, The Patriot Bldg. Parañaque City.

\title{
Thyroid Gland Invasion in Laryngeal Carcinoma
}

\begin{abstract}
Objective: To determine the prevalence of, and describe transglottic cancer with thyroid cartilage invasion as a possible risk for, thyroid gland invasion in a series of patients with laryngeal carcinoma who underwent total laryngectomy with thyroidectomy.
\end{abstract}

\section{Methods:}

\section{Design: $\quad$ Retrospective Case Series \\ Setting: $\quad$ Tertiary Government Training Hospital}

Participants: 61 laryngeal carcinoma patients who underwent total laryngectomy with hemi- or total thyroidectomy from January 2010 to August 2017.

Results: Out of 61 patients with laryngeal carcinoma, 11 patients had supraglottic, 11 glottic, 2 subglottic and 37 had transglottic involvement. Eleven had thyroid cartilage invasion, all of whom had transglottic tumors. Of these 11 patients, only 1 had thyroid gland invasion. This was a case of a 78 year-old male patient with poorly differentiated SCC stage IVa transglottic tumor with thyroid cartilage invasion.

Conclusion: Thyroid gland invasion was uncommon in our sample of laryngeal carcinoma patients who underwent laryngectomy and thyroidectomy. Although transglottic involvement with thyroid cartilage invasion may increase the risk of thyroid gland invasion, it could not be confirmed by our series. Perhaps thyroidectomy should not be routinely performed on all patients with laryngeal carcinoma who undergo total laryngectomy but more rigorous studies are needed to establish this.

Keywords: laryngeal carcinoma, transglottic, thyroid cartilage invasion, thyroid gland invasion, thyroidectomy

Total laryngectomy is the standard of care for operable squamous cell carcinoma (SCC) of the larynx. ${ }^{1-2}$ SCC of the larynx can spread to adjacent structures like the trachea, esophagus and thyroid gland. ${ }^{3}$ Invasion of the thyroid gland can be contiguous or non-contiguous via lymphovascular spread. ${ }^{4}$ The incidence of thyroid gland involvement in laryngo-pharyngeal cancer ranges from $0-23 \% .^{5-6}$

The need for thyroidectomy during total laryngectomy is controversial as thyroid gland invasion is rare and thyroidectomy is associated with long term morbidities..$^{7-8} \mathrm{~A}$ meta-analysis by Mendelson et al. advised hemithyroidectomy in transglottic tumors, subglottic tumors and tumors 
with subglottic extension more than $10 \mathrm{~mm} .{ }^{9}$ Other indications for thyroidectomy are palpable nodule, ${ }^{10} \mathrm{~T} 3$ and $\mathrm{T} 4$ lesion, ${ }^{5,9-13}$ transglottic growth, ${ }^{9-13}$ subglottic disease or extension more than $10 \mathrm{~mm}^{9-12,14-16}$ anterior commissure involvement ${ }^{5,12}$ and thyroid cartilage invasion. ${ }^{11}$ A local study revealed that extralaryngeal spread, tracheostomal involvement and tracheal extension were associated with thyroid gland invasion. ${ }^{17}$ However, despite all these studies, thyroidectomy is still routinely done for laryngectomy cases in our institution. The NCCN 2017 Guideline for laryngeal cancer states that for glottic and supraglottic T3 tumors requiring (amenable) to total laryngectomy can undergo the procedure with ipsilateral thyroidectomy. For patients with glottic and supraglottic T4a tumors, the standard approach is total laryngectomy with thyroidectomy and neck dissection as indicated (depending on node involevement) followed by adjuvant treatment. ${ }^{18}$ Studies in the local setting may change prevailing guidelines about the need for thyroidectomy in laryngectomy.

Our study aims to determine the prevalence of, and describe transglottic cancer with thyroid cartilage invasion as a possible risk for, thyroid gland invasion in a series of patients with laryngeal carcinoma who underwent total laryngectomy with thyroidectomy.

\section{METHODS}

With institutional Ethical Review Board approval, we retrieved records of all patients who underwent laryngectomy with thyroidectomy of any type at our institution from January 2010 to August 2017. Excluded were incomplete records and those of laryngectomy without histopathologically-documented thyroidectomy.

Demographics such as age and sex of the patients were obtained. The laryngeal tumor extent, type of thyroidectomy and thyroid gland involvement were recorded based on reported histological analysis of pathological specimens by different pathologists. Data were tabulated using MS Word for Mac 2011 version 14.0.0 (100825) (Microsoft Corporation, Redmond, WA, USA). Data were analyzed using Epi Info 2017 Version 7 (Centers for Disease Control and Prevention, Atlanta, GA, USA). A descriptive analysis was performed using frequency and proportion for each subsite of laryngeal carcinoma that was treated with total laryngectomy with or without thyroid cartilage involvement and with or without thyroid gland invasion and results evaluated in the light of the reviewed literature.

\section{RESULTS}

Records of 64 patients were initially considered but only 61 met the inclusion criteria. Of the 3 records excluded from the study, 2 were incomplete while 1 reported a total laryngectomy without thyroidectomy. Of the 61 patients included in the study, 58 (95.1\%) were males and $3(4.9 \%)$ were females. Their mean age was 62 years (range 48 to 78 years).

Twenty-seven patients underwent hemithyroidectomy (with isthmusectomy) while 34 had total thyroidectomy. Eleven had supraglottic involvement, 11 glottic, 2 subglottic and 37 transglottic. Out of the 37 transglottic cases, 11 had histopathologic thyroid cartilage invasion. Of these 11 transglottic cancers with thyroid cartilage involvement, only $1(1.6 \%)$ had histopathologically-confirmed thyroid gland invasion.

\section{DISCUSSION}

Our study had a $1.6 \%$ prevalence of thyroid gland invasion among patients who underwent total laryngectomy with thyroidectomy for laryngeal SCC. Previous studies show prevalences ranging from $1-11 \%, 1,11,14,15,17$ supportive of our findings that suggest thyroid gland invasion is uncommon in patients undergoing total laryngectomy for laryngeal SCC. Given the varied sample sizes and clinical scenarios of these studies, there seems to be no significant geographical difference in the incidence rate of thyroid gland invasion.

We were also interested in transglottic involvement with thyroid cartilage invasion as a possible risk for thyroid gland invasion. In our study, the prevalence of thyroid gland invasion increases to $2.7 \%$ if we consider only transglottic tumors (or 1 out of 37 patients). The lesion has to invade through thyroid cartilage, cricoid cartilage or cricothyroid membrane to reach the extralaryngeal soft tissue.' A retrospective study by lype et al. showed 30\% increase in thyroid gland invasion among patients with pre-operative findings of thyroid cartilage erosion by $\mathrm{CT}$ scan. ${ }^{16}$ In our study, there were 11 cases with thyroid cartilage invasion confirmed through histopathology, all of which were transglottic tumors. Among these, only one had positive thyroid gland invasion, increasing the risk to $9.1 \%$ or 1 out of 11 .

Laryngeal cancer is 4 times more common in males and $90 \%$ more common in patients more than 40 years old. ${ }^{9}$ Our patient with thyroid gland invasion was a 78 year-old male. It may be conjectured that he might have had ossified thyroid lamina that were more vulnerable to tumor invasion. Ossified portions of cartilage are potentially at higher risk for invasion because of vascular channel penetration, whereas intact perichondrium that surrounds avascular unossified cartilage resists tumor encroachment. ${ }^{19}$ Having said that, a meta-analysis by Mendelson et al. found that cartilaginous invasion by tumor was not a significant predictor of thyroid gland invasion. ${ }^{9}$

One drawback of the study is the limited number of cases with concomitant thyroid gland invasion. A multi- institutional study can be conducted to increase the number of cases. Another limitation is that it focused only on the subsite involved and presence of thyroid cartilage 


\section{ORIGINAL ARTICLES}

invasion as possible risk factors for having thyroid gland invasion. Other parameters such as size of mass, presence of palpable lymph nodes and involvement of anterior commissure as possible risk factors for having thyroid gland invasion can be included in future studies. The quality and reliability of second-hand data retrieved from patient records add another limitation to our study. For instance, our study design cannot account for variability in qualifications and competence among the different pathology residents and pathologists who evaluated and cut the gross specimens, read the slides and issued final histopathology reports. Future, controlled studies may address these issues.

Despite these considerations, thyroid gland invasion was uncommon in our sample of laryngeal carcinoma patients who underwent laryngectomy and thyroidectomy. Although transglottic involvement with thyroid cartilage invasion may increase the risk of thyroid gland invasion, it could not be confirmed by our series. Perhaps thyroidectomy should not be routinely performed on all patients with laryngeal carcinoma who undergo total laryngectomy but more rigorous studies are needed to establish this.

\section{REFERENCES}

1. Nayak SP, Singh V, Dan A, Bhownik A, Jadhav TS, Ashraf M. et al. Mechanism of thyroid gland invasion in laryngeal cancer and indications for thyroidectomy. Indian I Otolaryngol Head Neck Surg. 2013 Jul; 65(1): S69-S73. DOI: 10.1007/s12070-012-0530-9; PMID:24427619 PMCID: PMC3718952.

2. Armstrong W, Vokes D, Maisel R. Malignant tumors of the larynx. In: Flint P, Haughey B, Lund V, Niparko J, Richardson M, Robbins KT et al (editors). Cummings Otolaryngology Head and Neck Surgery. $5^{\text {th }}$ ed. Philadelphia: Mosby Elsevier. 2010.p. 1482.

3. Edge SB, Byrd DR, Compton CC, Fritz AG, Greene FL, Trotti A. AJCC cancer staging manual $7^{\text {th }}$ edition. Chapter 5 Larynx. New York: Springer; 2010.p. 58.

4. Gilbert RW, Cullen RJ, van Nostrand AW, Bryce DP, Harwood AR. Prognostic significance of thyroid gland involvement in laryngeal carcinoma. Arch Otolaryngology Head Neck Surg. 1986 Aug; 112(8):856-859. PMID: 3718691

5. Kim JW, Han GS, Byun SS, Lee DY, Cho BH, Kim YM. Management of thyroid gland invasion in laryngopharyngeal cancer. Auris Nasus Larynx. 2008 Jun; 35 (2):209-12 . DOl:10.1016/j. anl.2007.07.003; PMID: 17851001.

6. Croce A, Moretti A, Bianchedi M. Thyroid gland involvement in cancer of the larynx. Acta Otorhinolaryngoly Ital. 1991 Jul-Aug;11(4):429-35. PMID: 1792897.

7. Sinard RJ, Tobin EJ, Mazzaferri EL, Hodgson SE, Young DC, Kunz AL, et al. Hypothyroidism after treatment of non-thyroid head and neck cancer. Arch Otolarygol Head Neck Surg. 2000 May;126(5):652-57. PMID:10807335.

8. Ho AC, Ho WK, Lam PK, Yeun AP, Wei WI. Thyroid dysfunction in laryngectomies - 10 years after treatment. Head Neck. 2008 Mar;30(3):336-40. DOl10.1002/hed.20693; PMID: 17636544.

9. Mendelson AA, Al-Khatib TA, Julien M, Payne RJ, Black MJ, Hier MP. Thyroid gland management in total laryngectomy: meta-analysis and surgical recommendations. Otolaryngol Head Neck Surg 2009 Mar; 140(3): 298-305. DOI: 10.1016/j.otohns.2008.10.031; PMID: 19248932.

10. Biel MA, Maisel RH. Indications for performing hemi- thyroidectomy for tumours requiring total laryngectomy. Am J Surg. 1985 Oct; 150:435-439. PMID: 4051106.

11. Dadas B, Uslu B, Cakir B, Ozdogan HC, Calis AB, Turgut S. Intraoperative management of the thyroid gland in laryngeal cancer surgery. J Otolaryngol. 2001 Jun; 30(3):179-183. PMID:11771049.

12. Brennan JA, Meyers AD, Jafek BW. The intraoperative management of the thyroid gland during laryngectomy. Laryngoscope. 1991 Sep;101(9):929-934. DOI:10.1288/00005537-19910900000003; PMID: 1886441.

13. Gallegos-Hernandez JF, Minauro-Munoz G, Hernandez DM, Flores-Carranza A, HernandezSanjuan M, Resendiz-Colosia JA. Thyroidectomy associated with laryngectomy in laryngeal cancer treatment. Is it routinely necessary? Cir. 2005 Jan-Feb; 73(1):3-6. PMID: 15888262.

14. Al-Khatib T, Mendelson AA, Kost K, Zeitouni A, Black M, Payne R, et al. Routine thyroidectomy in total laryngectomy: is it really indicated? J Otolaryngoly Head Neck Surg. 2009 Oct; 38(5):564567. PMID: 19769827

15. Kumar R, Drinnan M, Robinson M, Meikle D, Stafford F, Welch A et al. Thyroid gland invasion in total laryngectomy and total laryngopharyngectomy: a systematic review and meta-analysis of the English literature. Clin Otolaryngol. 2013 Oct; 38(5): 372-8. DOI: 10.1111/coa.12165; PMID: 23998197

16. Iype EM, Jagad V, Nochikattil SK, Varghese BT, Sebastian P. Thyroid gland involvement in carcinoma of larynx and hypopharynx- predictive factors and prognostic significance. J Clin Diagn Res. 2016 Feb; 10(2): XCO5-XCO7. DOI: 10.7860/JCDR/2016/15225.7310; PMID: 27042568 PMCID: PMC4800634.

17. Holgado J, Grullo P, Gloria J, Pontejos A. Thyroid gland involvement in advanced laryngeal squamous cell carcinoma. Acta Medica Philippina. 2017 Jan; 51 (1): p. 11-13.

18. Pfister D, Spencer S, Adelstein D, Adkins D, Brizel D, Burtness B, et al. National Comprehensive Cancer Network Clinical Practice Guidelines in Oncology Version 1. 2017. [accessed 2017 Feb 6]. Available from: https://www.ncen.org/.

19. Parsons M, Stachecki R, Wippold F. Diagnostic imaging of the larynx. In: Flint P, Haughey B, Robbins K, Thomas J, Niparko J, Lund VJ et al (editors). Cummings Otolaryngology Head and Neck Surgery. $6^{\text {th }}$ ed. Philadelphia: Saunders. 2015.p. 1592. 